\title{
Non-DHFR-mediated effects of methotrexate in osteosarcoma cell lines: epigenetic alterations and enhanced cell differentiation
}

\author{
Martin Sramek ${ }^{1,2}$, Jakub Neradil ${ }^{1,2}$, Jaroslav Sterba ${ }^{2}$ and Renata Veselska1,2*
}

\begin{abstract}
Background: Methotrexate is an important chemotherapeutic drug widely known as an inhibitor of dihydrofolate reductase (DHFR) which inhibits the reduction of folic acid. DHFR-mediated effects are apparently responsible for its primary antineoplastic action. However, other non-DHFR-mediated effects of methotrexate have been recently discovered, which might be very useful in the development of new strategies for the treatment of pediatric malignancies. The principal goal of this study was to analyze the possible impact of clinically achievable methotrexate levels on cell proliferation, mechanisms of epigenetic regulation (DNA methylation and histone acetylation), induced differentiation and the expression of differentiation-related genes in six osteosarcoma cell lines.
\end{abstract}

Methods: The Saos-2 reference cell line and five other patient-derived osteosarcoma cell lines were chosen for this study. The MTT assay was used to assess cell proliferation, DNA methylation and histone acetylation were detected using ELISA, and western blotting was used for a detailed analysis of histone acetylation. The expression of differentiation-related genes was quantified using RT-qPCR and the course of cell differentiation was evaluated using Alizarin Red S staining, which detects the level of extracellular matrix mineralization.

Results: Methotrexate significantly decreased the proliferation of Saos-2 cells exclusively, suggesting that this reference cell line was sensitive to the DHFR-mediated effects of methotrexate. In contrast, other results indicated non-DHFR-mediated effects in patient-derived cell lines. Methotrexate-induced DNA demethylation was detected in almost all of them; methotrexate was able to lower the level of 5-methylcytosine in treated cells, and this effect was similar to the effect of 5-aza-2'-deoxycytidine. Furthermore, methotrexate increased the level of acetylated histone $\mathrm{H} 3$ in the OSA-06 cell line. Methotrexate also enhanced all-trans retinoic acid-induced cell differentiation in three patient-derived osteosarcoma cell lines, and the modulation of expression of the differentiation-related genes was also shown.

Conclusions: Overall non-DHFR-mediated effects of methotrexate were detected in the patient-derived osteosarcoma cell lines. Methotrexate acts as an epigenetic modifier and has a potential impact on cell differentiation and the expression of related genes. Furthermore, the combination of methotrexate and all-trans retinoic acid can be effective as a differentiation therapy for osteosarcoma.

Keywords: Methotrexate, Osteosarcoma, Epigenetic regulation, DNA methylation, Histone acetylation, All-trans retinoic acid, Osteogenic differentiation

\footnotetext{
*Correspondence: veselska@sci.muni.cz

${ }^{1}$ Laboratory of Tumor Biology, Department of Experimental Biology,

Faculty of Science, Masaryk University, Kotlarska 2, 61137 Brno, Czech

Republic

Full list of author information is available at the end of the article
} 


\section{Background}

Methotrexate (MTX; amethopterin; 4-amino-10-methylfolic acid), a structural analogue of folic acid, is a chemotherapeutic drug which is still very frequently used as a treatment of osteosarcomas-the most common primary malignant bone tumors affecting both children and adults [1]. MTX has been included in therapeutic protocols for many years, but its dosage and administration schedules are still being optimized [2, 3].

MTX enters the cell through an active transport mechanism and by facilitated diffusion, and once inside, it is converted into polyglutamate MTX by folylpolyglutamyl synthase [4-6]. Polyglutamate MTX reversibly inhibits dihydrofolate reductase (DHFR) but also inhibits other enzymes, for example, phosphoribosylaminoimidazolecarboxamide formyltransferase (AICAR transformylase) or thymidylate synthase (TS). Inhibition of DHFR affects the reduction of folic acid and consequently leads to a lack of 5,10-methylenetetrahydrofolate, which is used as a coenzyme in the biosynthesis of thymidine. Moreover, TS is directly blocked by MTX and by unmetabolized dihydrofolate. Purine precursor biosynthesis is also affected by the deficiency of another folate co-factor, 10-formyltetrahydrofolate and by MTX inhibition of AICAR transformylase. The inhibition of dTMP and purine synthesis causes MTX-induced cell death [7].

Although MTX is able to inhibit proliferation and/ or induce apoptosis in neoplastic cells, there is also evidence that it induces differentiation. MTX was able to induce differentiation in colon cancer cells primarily due to the intracellular depletion of purines [8], in immature and undifferentiated monocytic cells [9] and in rat choriocarcinoma cells [10]. Overall, cytostatic, cytotoxic and differentiation effects are mediated by the functional suppression of DHFR and nucleotide biosynthesis.

In addition to the cytostatic and differentiation effects of MTX, non-DHFR-mediated effects concerning the modulation of important epigenetics determinants have also been described, such as DNA methylation [11] and histone acetylation [12]. The mechanism of the methylation of biomolecules is not always clear because both the DHFR- and non-DHFR-mediated effects of MTX can contribute to the decreased methylation of molecules in the cell. On one hand, inhibition of folate metabolism as described above can affect the intracellular levels of 5-methyltetrahydrofolate which transfers methyl groups to methionine synthase to generate methionine from homocysteine [13]. Methionine can be utilized for the synthesis of the universal methyl donor S-adenosylmethionine (SAM) which plays a pivotal role in the generation of 5-methylcytosine. On the other hand, MTX directly inhibits methionine adenosyltransferase (MAT) mRNA expression and reduces MAT protein levels which significantly decreases MAT activity [13]. This is of particular importance because MAT is a key enzyme that catalyzes the only reaction that produces SAM. Moreover, MAT expression and activity can be inhibited even by a very low concentration of MTX $(50 \mathrm{nmol})$. Regarding histone acetylation, molecular modeling suggested that MTX is a potential histone deacetylase inhibitor due to its shared structural similarity with some histone deacetylase inhibitors (e.g., butyrate or trichostatin A), and it has been shown that MTX directly inhibits histone deacetylase activity and induces histone $\mathrm{H} 3$ acetylation in vitro [12].

It has been shown that the induced differentiation of tumor cells is a promising strategy in cancer therapy [14]. Especially, all-trans retinoic acid (ATRA) and its derivatives are widely used differentiation drugs that can induce the osteogenic differentiation of osteosarcoma cells [15]. The main disadvantage of retinoid usage is the occurrence of resistance [16]. On one hand, DNA methylation has a significant role in preventing normal differentiation in pediatric cancers [17], and on the other hand, DNA demethylation can contribute to cell differentiation; for example, the expression of the retinoic acid receptor beta $(R A R B)$ can be activated by the hypomethylating action of 5-aza-2'-deoxycytidine [18]. Histones are involved in the regulation of chromatin structure and gene expression as well as in DNA methylation. Histone H3 acetylation is also associated with gene expression. Therefore, due to its impact on nucleotide synthesis, as well as DNA methylation and histone acetylation, MTX could modulate gene expression and enhance the ATRA-induced differentiation of osteosarcoma cells.

In the present study, we focused on MTX action in six cell lines derived from osteosarcomas. The MTX effect on DNA methylation was compared with the effect of the known DNA methyltransferase inhibitor 5-aza-2'deoxycytidine (5AZA), and the accumulation of acetyl histone $\mathrm{H} 3$ after MTX treatment was compared with the effects of the known histone deacetylase inhibitors sodium butyrate (BUT) and sodium valproate (VAL). We also studied the MTX impact on the expression of selected genes related to cell differentiation, and we assessed cell differentiation induced by MTX, ATRA or a combination of the two. Therefore, our work represents the first complex study of the non-DHFR-mediated effects of MTX in cancer cells with special attention to the modulation of epigenetic information in terms of DNA methylation and histone acetylation.

\section{Results}

Our results showed that the non-DHFR mediated effects of MTX were detectable, especially in patient-derived cell lines and that MTX act as an epigenetic modifier with an impact both on DNA demethylation and the accumulation 
of acetylated histones. Moreover, the combination of MTX and ATRA may represent a new therapeutic option in the differentiation therapy of osteosarcoma.

\section{Patient-derived cell lines are more resistant to MTX than Saos-2 cell line}

Using the MTT assay, an analysis of proliferation activity was performed on day 6 of MTX treatment at concentrations from 0.0001 to $100 \mu \mathrm{M}$. Significant differences in the sensitivity of cell lines used in this study (Fig. 1) were noted. On one hand, MTX showed a strong cytotoxic effect on the Saos-2 reference cell line at concentrations ranging from 0.1 to $100 \mu \mathrm{M}$. On the other hand, all five patient-derived OSA cell lines were significantly more resistant to MTX action, and even the very high concentration of $100 \mu \mathrm{M}$ was not sufficient to reach the $\mathrm{IC}_{50}$.

\section{MTX induces DNA demethylation in a majority of osteosarcoma cell lines}

Despite the mild effect of MTX on cell proliferation, we continued to study the non-DHFR-mediated effects of MTX on DNA methylation. Significant DNA demethylation was observed in Saos-2, OSA-03, OSA-05, OSA-06 and OSA-08 cells at day 3 of the MTX treatment, especially at a concentration of $40 \mu \mathrm{M}$ (Fig. 2). The MTXinduced DNA demethylation was most obvious in the OSA-06 cells-the level of 5-methylcytosine decreased to $86 \%$ at $1 \mu \mathrm{M}$ MTX and to $76 \%$ at $40 \mu \mathrm{M}$ MTX in

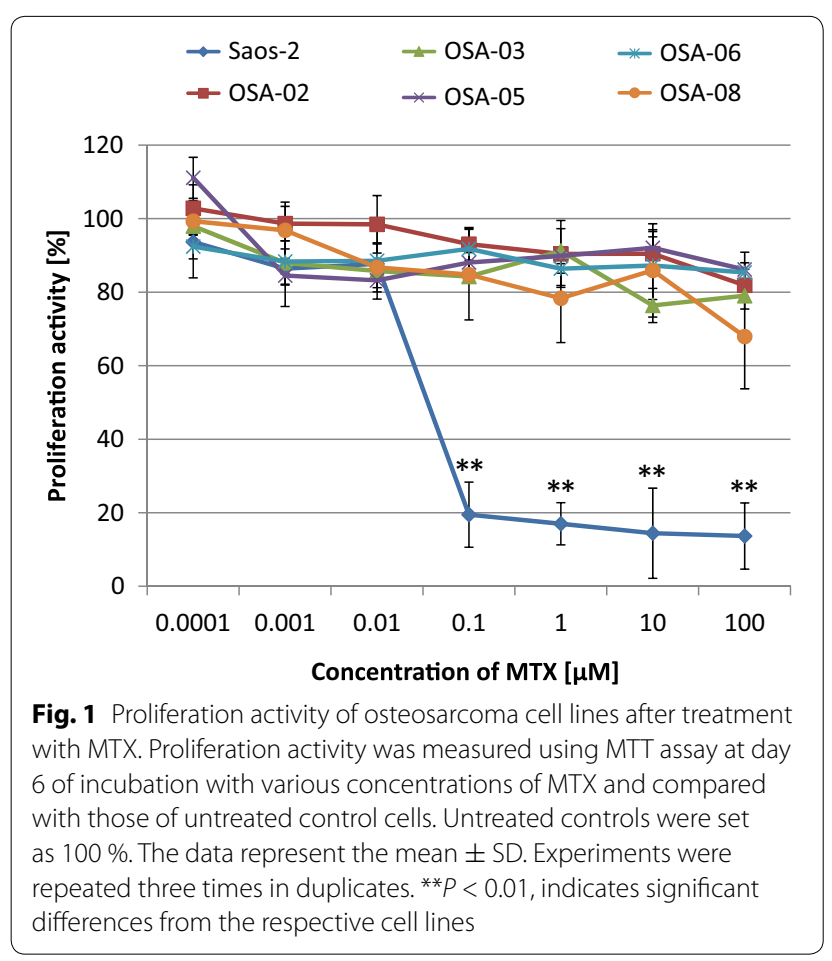

comparison with untreated control cells. As expected, the positive control 5AZA induced DNA demethylation in Saos-2, OSA-03, OSA-05, OSA-06 and OSA-08. Surprisingly in Saos-2, OSA-03, OSA-05 and OSA-06 cells, $40 \mu \mathrm{M}$ MTX induced DNA demethylation comparable to the effect of 5AZA at the same concentration. We did not observe any changes in DNA methylation in OSA-02 cells.

\section{MTX increases the global histone H3 acetylation in OSA-06 cells}

Given that MTX is a possible histone deacetylase inhibitor, we determined whether MTX could increase histone $\mathrm{H} 3$ acetylation. Treatment with BUT and VAL served as a positive controls and, in some cases, treated cells showed the significant accumulation of acetylated histone $\mathrm{H} 3$ in comparison with an untreated control (Fig. 3). We did not detect an increase in the global acetylation of histone $\mathrm{H} 3$ at day 3 of the MTX treatment in Saos-2, OSA-02, OSA-03, OSA-05 and OSA-08 cells (Fig. 3a-d, f); however, we observed an increase of histone $\mathrm{H} 3$ acetylation in OSA-06 cells (Fig. 3e), and therefore, this cell line was further analyzed using western blotting. Cells were incubated with MTX, VAL or BUT, and the nuclear protein fractions were harvested and immunoblotted on day 3 of the treatment (Fig. 4). Our data demonstrated that MTX increased histone $\mathrm{H} 3$ acetylation in OSA-06 cells in a concentration-dependent manner.

\section{MTX alters the expression of differentiation-related genes}

To further explore the importance of epigenetic alterations induced by MTX, we decided to assess the MTX impact on the expression of selected genes involved in cell differentiation. The expression of genes encoding known markers of osteogenic differentiation (COLLI, $A L P L)$ as well as genes involved in ATRA metabolism and the regulation of gene expression were evaluated using RT-qPCR on day 3 of MTX treatment at concentrations of $1 \mu \mathrm{M}$ and $40 \mu \mathrm{M}$ (Fig. 5). In Saos-2 cells, we observed a significant increase in the expression of $R A R A, C R B P 1$ and $C R A B P 2$. Interestingly, the expression of $C R A B P 2$ was increased approximately ten-fold, but the expression of $R A R B$ and $A L P L$ was significantly lower (Fig. 5a). In OSA-02 cells, MTX at both concentrations significantly increased the expression of $R A R A$ and also the expression of COLLI at $40 \mu \mathrm{M}$. In contrast, the expression of CRBP1 was at a very low level (Fig. 5b). In OSA-03 cells, COLLI expression was significantly higher after treatment with $40 \mu \mathrm{M}$ MTX, but the same concentration of MTX significantly decreased the expression of $C R A B P 2$ and $A L P L$ (Fig. 5c). In OSA-05 cells, $1 \mu \mathrm{M}$ MTX significantly increased the expression of $R A R A, R A R B$ and $R X R A$ (Fig. $5 \mathrm{~d}$ ). In OSA-06 cells, MTX significantly 
a

Saos-2

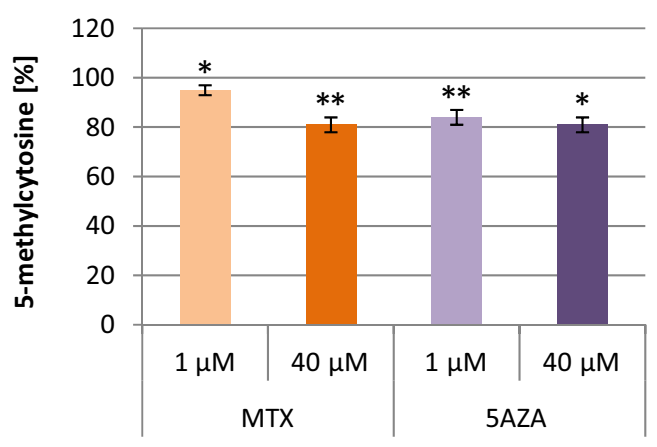

C

OSA-03

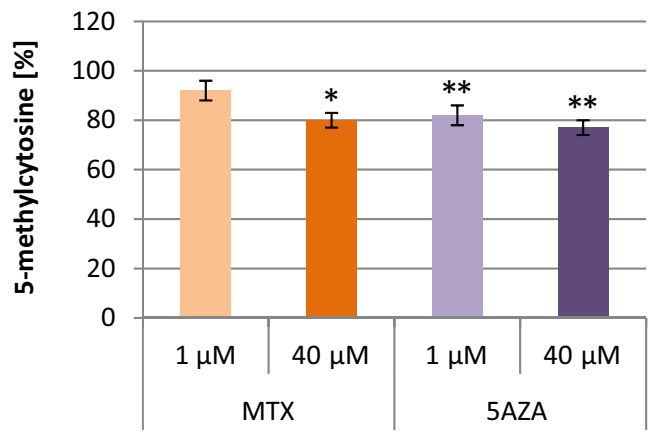

e

OSA-06

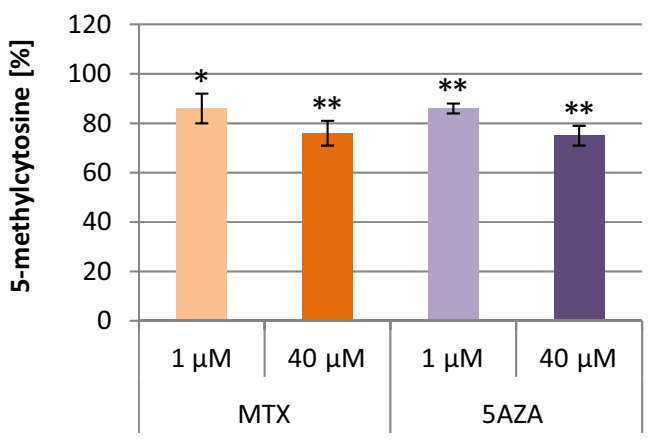

b

OSA-02

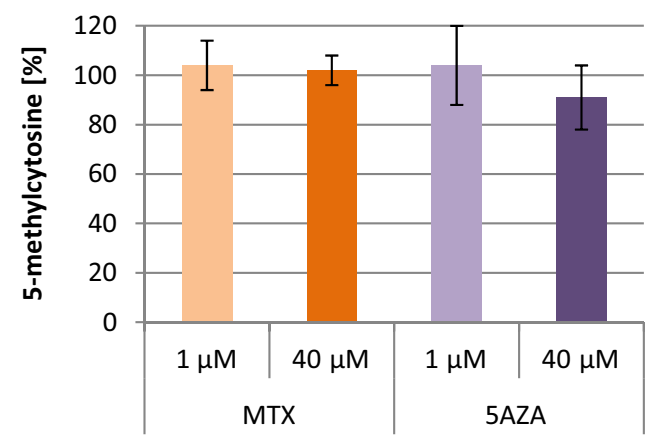

d

OSA-05

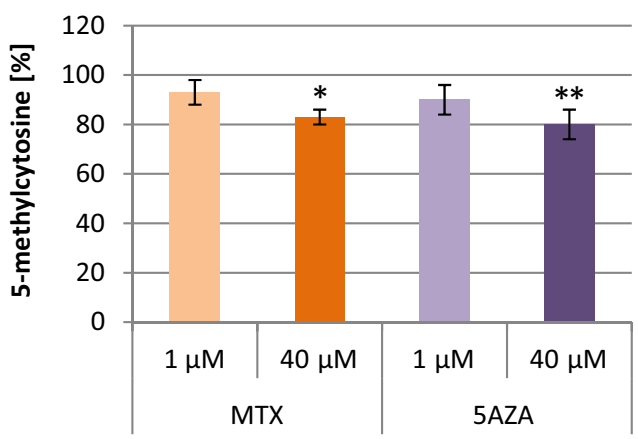

$\mathbf{f}$

OSA-08

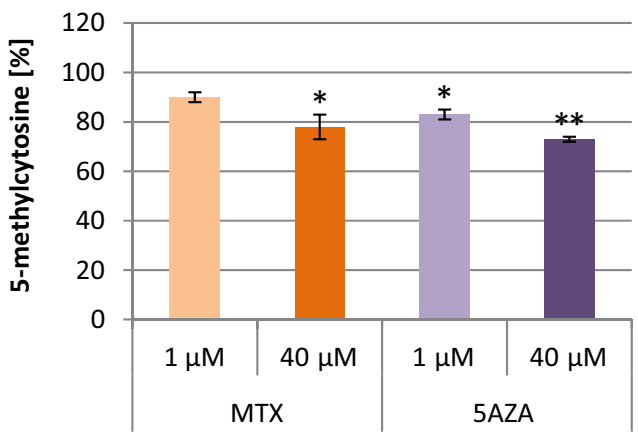

Fig. 2 Changes in DNA methylation in osteosarcoma cell lines after treatment with MTX. Levels of 5-methylcytosine in Saos-2 (a), OSA-02 (b), OSA03 (c), OSA-05 (d), OSA-06 (e) and OSA-08 (f) cells as measured using an ELISA assay at day 3 of incubation. The levels of 5-methylcytosine are presented as a percentage change compared to the levels found in untreated control cells. Untreated controls were set as $100 \%$. The data represent the mean $\pm S D$. Experiments were repeated three times. ${ }^{*} P<0.05,{ }^{* *} P<0.01$, indicate significant differences from the respective control groups

decreased the expression of $C R A B P 2$ only (Fig. 5e). In OSA-08 cells, the expression of RARA and CRBP1 was significantly increased after MTX treatment (Fig. 5f).

\section{Osteogenic differentiation is enhanced by combined treatment with MTX and ATRA}

As indicated by the previous analyses, MTX treatment significantly increased the expression of some genes involved in ATRA metabolism and the regulation of gene expression. This observation led us to explore whether MTX could enhance ATRA-induced differentiation. After 21 days of cultivation, all cell lines formed calcium-positive nodules in control cell populations as well as under all experimental conditions. In the Saos- 2 cell line, MTX significantly enhanced the extent of this mineralization (Fig. 6a), but MTX-induced mineralization was less apparent in all five OSA cell lines (Fig. 6b-f). ATRA significantly enhanced the mineralization in Saos-2 cells in a manner 


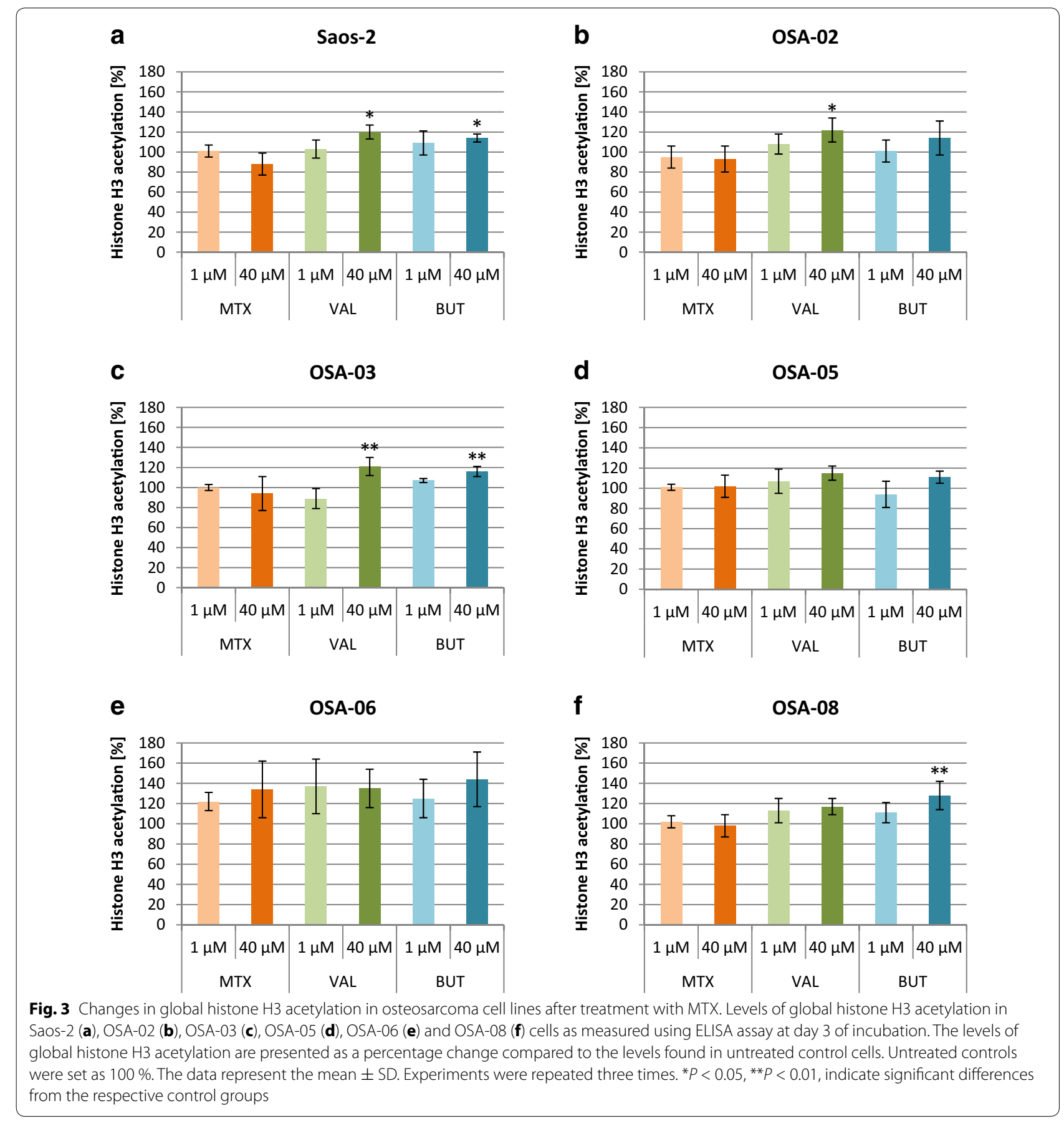

similar to MTX. In all OSA cell lines ATRA was always more effective in enhancing mineralization than MTX and in all cases significantly enhanced the extent of the mineralization. The combination of ATRA $(0.1$ or $1 \mu \mathrm{M})$ and MTX $(1$ or $40 \mu \mathrm{M})$ did not have an additional effect on the amount of calcium sediments in Saos-2, OSA-02 and
OSA-08 cell lines. Interestingly, in the OSA-03, OSA-05 and OSA-06 cell lines, a combined treatment with ATRA and MTX significantly enhanced the mineralization in comparison with the untreated control by $21-28 \%$. The greatest increase in mineralization with the combined treatment was found in the OSA-06 cell line (Fig. 6e). 


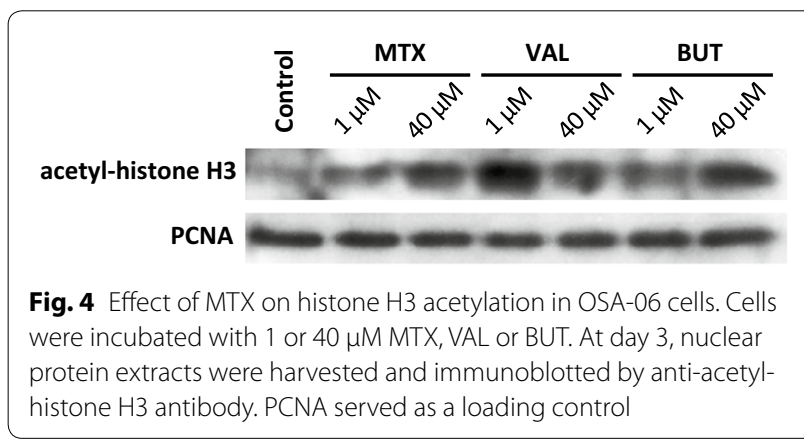

\section{Discussion}

For decades, MTX was a commonly used therapy in osteosarcoma patients [19]. MTX interferes with folate metabolism but its other antineoplastic effects are still being discovered, and these effects can be helpful in the development of new strategies for osteosarcoma treatment [20]. The principal goals of this study were to analyze the non-DHFR-mediated effects of MTX in cell lines derived from osteosarcomas and to determine whether MTX acts as an epigenetic modifier in terms of DNA demethylation, histone acetylation, subsequent changes in gene expression and induced cell differentiation. The Saos- 2 osteosarcoma cell line was chosen as the reference cell line for this study, and it was compared with five other cell lines that were derived in our laboratory from biopsy samples taken from patients suffering with osteosarcoma [21].

The MTT assay indicated that Saos- 2 cells were very sensitive to MTX treatment, which showed a strong cytotoxic effect in these cells at $0.1 \mu \mathrm{M}$. This observation is in full accordance with our previous study [22] and with results obtained by other research groups studying the sensitivity of Saos- 2 cells to MTX [23]. All five OSA cell lines, which were derived from diagnostic biopsies of primary tumors without any previous neoadjuvant chemotherapy, were significantly more resistant to the DHFR-mediated effect of MTX than Saos-2 cell line. The resistance of the OSA cell lines is surprising when we consider that $40 \mu \mathrm{M}$ MTX is comparable with the peak of the MTX plasma concentration achieved during high dose-MTX treatments of pediatric hematological malignancies. In osteosarcomas, the peak MTX levels are approximately $1000 \mu \mathrm{M}$ but rapidly decline within hours. Altogether, these results show that lower levels of MTX could not fully inhibit DHFR and nucleotide biosynthesis in all OSA cell lines despite prolonged exposure [24]. Furthermore, all OSA cells showed a low doubling time in comparison with Saos-2 cells that could diminish the proliferation-dependent cytotoxicity of MTX [25]. Other possible mechanisms of MTX resistance are an augmented drug efflux, impaired intracellular polyglutamation or alterations in the activity of target enzymes [6].

Because we did not observe any profound negative DHFR-mediated impact of MTX on cell proliferation in almost all of the cell lines included in this study, we continued with experiments that focused on other possible non-DHFR-mediated effects of MTX on osteosarcoma cells. MTX decreases the concentration of 5-methyltetrahydrofolate [26, 27] and reduces MAT expression and activity [13], which can further affect methylation in treated cells. 5-methyltetrahydrofolate and homocysteine are two important molecules in methionine biosynthesis [28]. Methionine reacts with ATP, and SAM is formed as a product. This key reaction is catalyzed by MAT. A methyl group from SAM is enzymatically transferred to the 5-position of cytosine to generate 5-methylcytosine in genomic DNA. Our data demonstrate that MTX significantly decreased 5-methylcytosine levels in genomic DNA and induce global genomic DNA demethylation. Surprisingly, significant DNA demethylation was observed in almost all of the cell lines used in our experiments.

Due to the similar structure of MTX and known histone deacetylase inhibitors, e.g., butyrate and trichostatin A, MTX can inhibit histone deacetylase activity and induce histone $\mathrm{H} 3$ acetylation [12]. Nevertheless, the five cell lines in our study including Saos-2 showed a poor response to MTX in this aspect. Only the OSA-06 cell line has a higher level of acetyl histone H3 after MTX treatment. Therefore, OSA-06 cells were further analyzed by western blotting to confirm this effect and the results showed that MTX increased the level of acetylated histone $\mathrm{H} 3$ in this cell line. As expected, most of cell lines showed a significant increase in the amount of acetylated histone $\mathrm{H} 3$ after treatment with BUT or VAL.

In contrast, MTX changed the methylation status of DNA in almost all of the studied cell lines. This finding led us to explore two important issues: (i) alterations of expression of the selected genes in MTX-treated cells and (ii) effect of MTX on differentiation in osteosarcoma cells after a combined treatment with ATRA because ATRA is a widely used inducer of differentiation in osteosarcoma cells $[15,29,30]$.

Both of these aspects are important and mutually interconnected. Inducing differentiation of tumor cells by retinoids seems to be a very promising strategy, but it can be complicated by the resistance of tumor cells $[16,31-$ 33]. The regulation of cell differentiation by retinoids is mediated by two types of nuclear receptors: retinoic acid receptors (RAR) and retinoid X receptors (RXR). DNA methylation patterns could affect the normal course of the expression of genes involved in cell differentiation [34]. For instance, $R A R B$ is methylated in many breast 
a

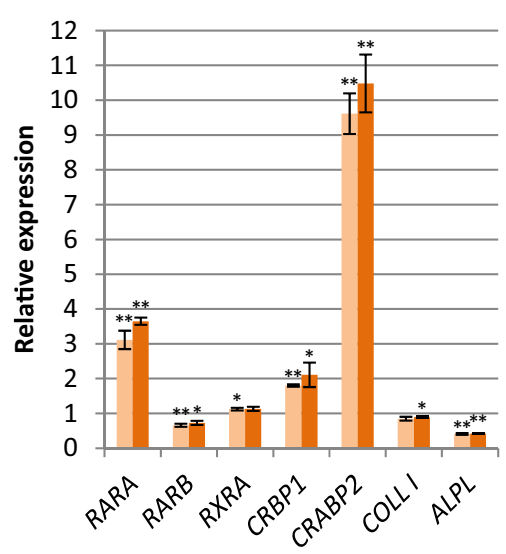

C

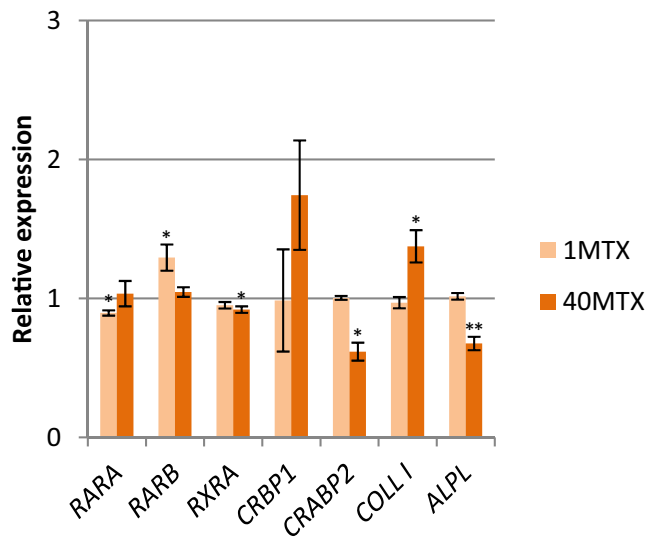

e

OSA-06

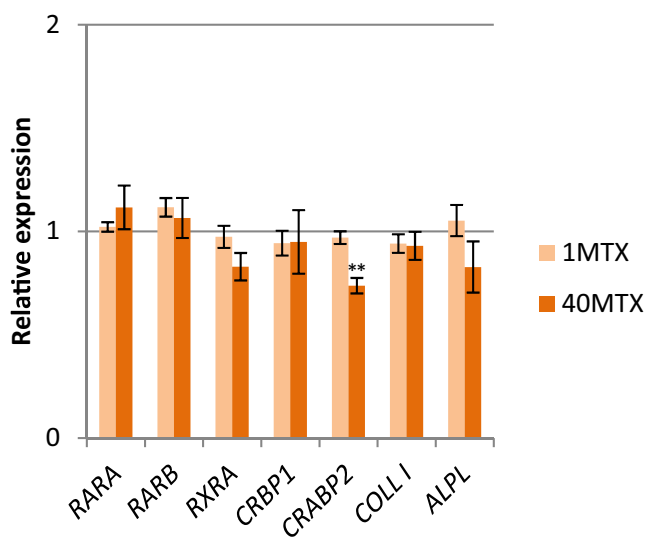

b

OSA-02

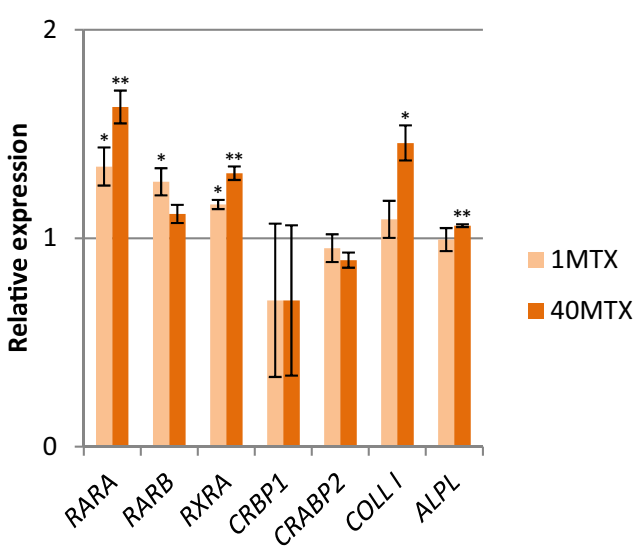

d OSA-05

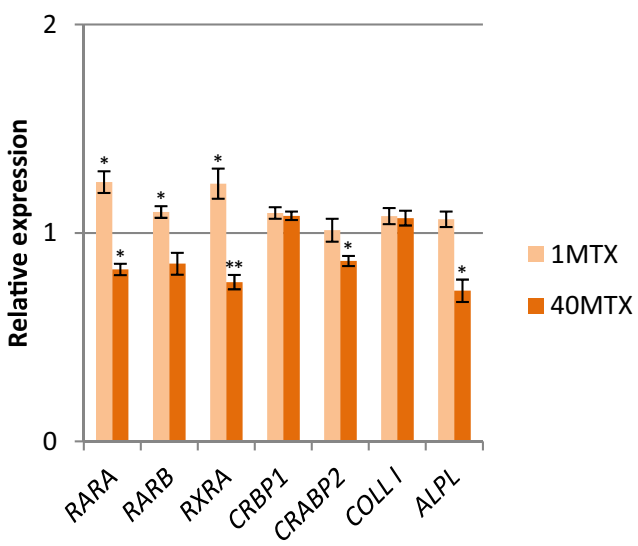

f

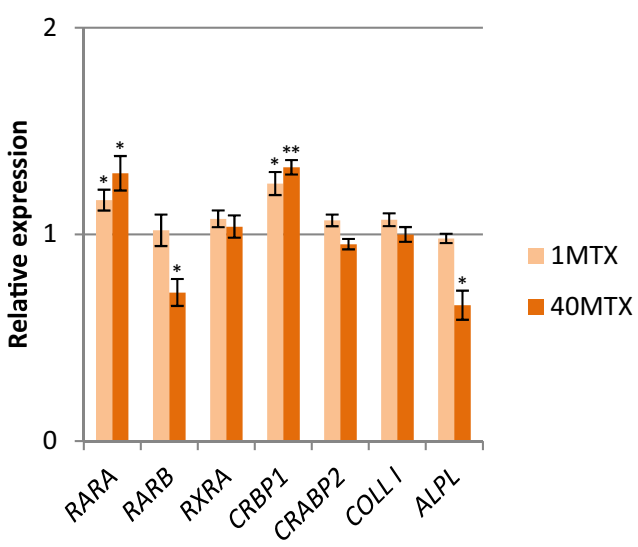

Fig. 5 Changes in expression of differentiation-related genes in osteosarcoma cell lines after treatment with MTX. The relative expression of selected genes in Saos-2 (a), OSA-02 (b), OSA-03 (c), OSA-05 (d), OSA-06 (e) and OSA-08 (f) cells measured using RT-qPCR at day 3 of incubation with $1 \mu \mathrm{M}$ MTX (1MTX) or with $40 \mu \mathrm{M}$ MTX (40MTX). The levels of relative gene expression are presented as fold changes compared to the levels detected in control samples. The data represent the mean \pm SD. Experiments were repeated three times. ${ }^{*} P<0.05,{ }^{* *} P<0.01$, indicate significant differences from the respective control groups 
a

Saos-2

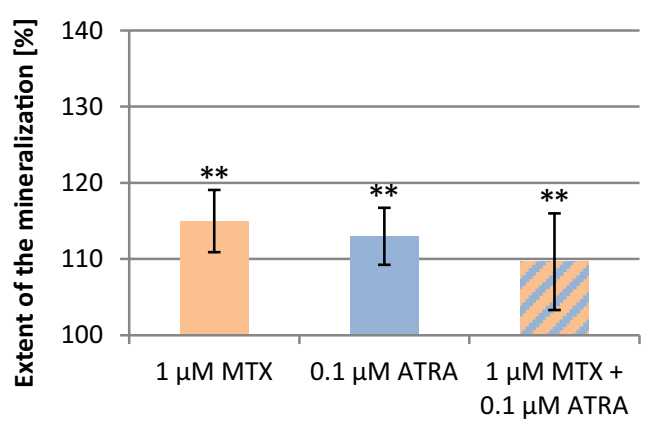

C

OSA-03

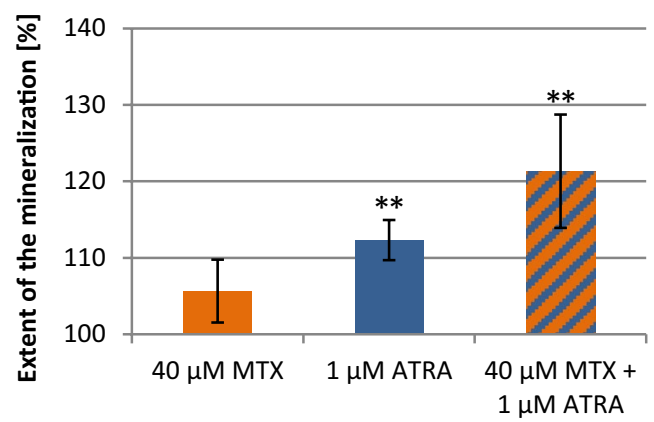

e

OSA-06

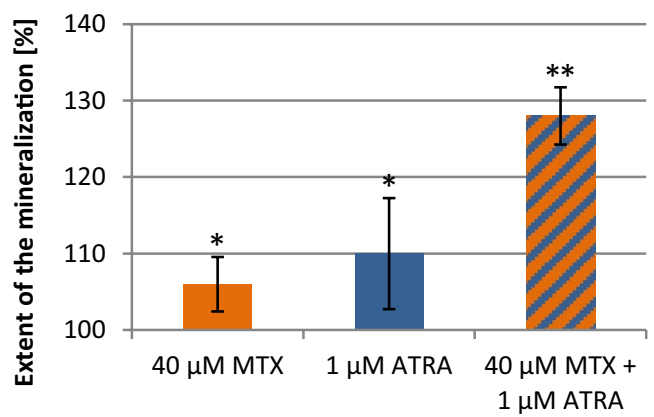

b

OSA-02

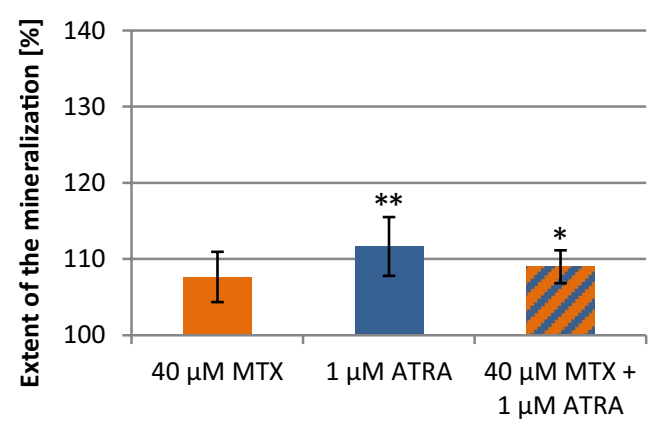

d

OSA-05

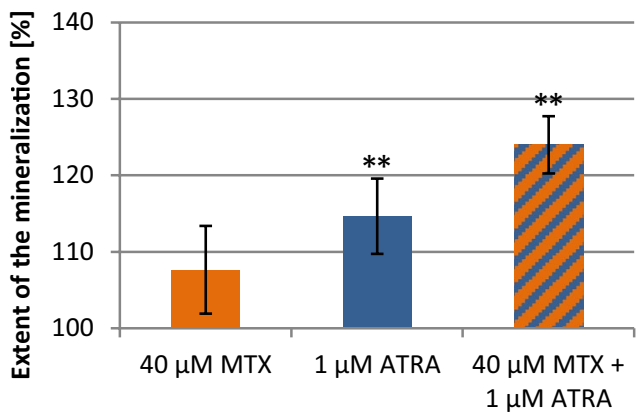

OSA-08

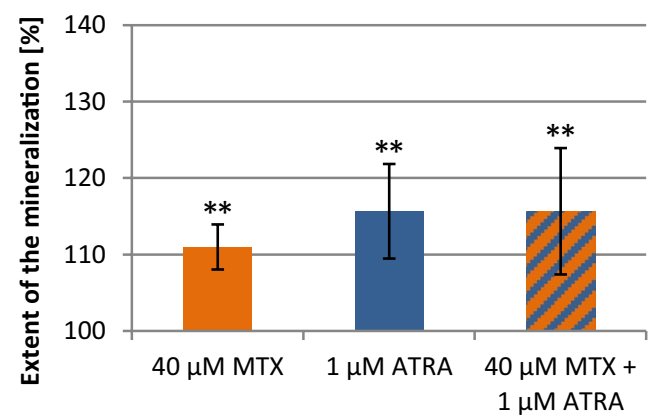

Fig. 6 Changes in matrix mineralization in osteosarcoma cell lines after treatment with MTX. Saos-2 (a), OSA-02 (b), OSA-03 (c), OSA-05 (d), OSA-06 (e) and OSA-08 (f) cell lines treated with MTX and/or ATRA were measured using staining with Alizarin Red S at day 21 of incubation. The extent of mineralization is presented as a percentage change compared to the levels found in untreated control cells. Untreated controls were set as $100 \%$. The data represent the mean $\pm S D$. Experiments were repeated three times. ${ }^{*} P<0.05,{ }^{* *} P<0.01$, indicate significant differences from the respective control groups

cancer cell lines and treatment of these cell lines with a demethylating agent can restore inducibility of $R A R B$ by ATRA [35]. Other studies have demonstrated that the $R A R B$ promoter is hypermethylated in colorectal and lung carcinomas and that this methylation could account for the $R A R B$ downregulation $[18,36]$.

At first, we studied whether MTX could modulate the expression of genes involved in retinoid/ATRA metabolism and signaling and whether MTX alone could induce differentiation in osteosarcoma cells. After treatment with MTX, we observed that the RARA was significantly highly expressed in Saos-2 and OSA-02 cells. Another interesting observation was the significantly increased expression of CRABP2 in Saos-2 cells. CRABP2 encodes the cytosol-to-nuclear shuttling protein, which facilitates the binding of retinoic acid to its receptor and the transfer of this complex to the nucleus. Furthermore, the expression CRBP1, which encodes the carrier protein 
involved in the transport of retinol from liver storage site to the peripheral tissue was also significantly elevated in Saos- 2 cells as well as in OSA-08 cells.

Regarding osteogenic differentiation, we examined the expression of known osteogenic differentiation markers, i.e., collagen type I (COLLI) and alkaline phosphatase $(A L P L)$ [30]. Increase in COLLI expression is typical in the early stages of differentiation whereas levels of $A L P L$ usually increase during the process of mineralization, i.e., during the late stages of induced differentiation [37]. Nevertheless, we did not observe a marked increase in expression of these markers.

Because the expression of some differentiation-related genes was modulated after 3 days of MTX treatment, we decided to evaluate a long time course of osteogenic differentiation using mineralization measured by Alizarin Red S staining [30]. MTX and ATRA alone increased the extent of matrix mineralization in all cell lines but ATRA was apparently more effective. Interestingly, MTX alone was able to induce cell differentiation effectively in the Saos- 2 cell line; this finding is in accordance with previously published results on choriocarcinoma cells [38]. Our data also demonstrated that a combined treatment with ATRA and MTX enhanced matrix mineralization most greatly in the OSA-03, OSA-05 and OSA-06 cell lines, so the combined administration of MTX and retinoids could be effective in differentiation therapy of some osteosarcomas.

\section{Conclusions}

To summarize, our study represents the first complex analysis of the non-DHFR-mediated effects of MTX on cell lines derived from osteosarcomas. We showed that MTX treatment significantly decreased the proliferation activity in the Saos-2 reference cell line, but all five patient-derived OSA cell lines were much less sensitive to MTX action. These results suggest that all OSA cell lines were not sensitive to the DHFR-mediated effects of MTX at concentrations used. More importantly, our results provide the evidence for non-DHFR-mediated effects of MTX in both Saos-2 and OSA cell lines. MTX could act as an epigenetic modifier because (1) it induced significant DNA demethylation in almost all of the studied osteosarcoma cells and (2) it increased the global acetylation of histone $\mathrm{H} 3$ in OSA-06 cells. Our findings also demonstrated the modulation of the expression of differentiation-related genes by MTX at certain concentrations. The most important result of our study showed that ATRA-induced cell differentiation might be enhanced by the combined treatment of cells with MTX; this implies new possibilities in administration of these drugs in clinical practice.

\section{Methods}

\section{Cell culture}

The Saos-2 cell line (No. HTB-85) was purchased from the American Type Culture Collection (Manassas, VA, USA). The OSA-02, OSA-03, OSA-05, OSA-06 and OSA08 cell lines were derived in our laboratory from tumor samples obtained from patients surgically treated for osteosarcoma as previously described [21]. A description of the cell lines included in this study and their responses to MTX is provided in Table 1. The Research Ethics Committee of the School of Medicine (Masaryk University, Brno, Czech Republic) approved the study protocol and a written statement of informed consent was obtained from each patient or his/her legal guardian.

Cells were grown in Dulbecco's modified Eagle's medium (DMEM) supplemented with $10 \%$ (Saos-2) or $20 \%$ (OSA-02, OSA-03, OSA-05, OSA-06 and OSA08) fetal bovine serum, $100 \mathrm{IU} / \mathrm{ml}$ penicillin, $100 \mathrm{mg} / \mathrm{ml}$ streptomycin, and $2 \mathrm{mM}$ glutamine (all purchased from GE Healthcare Europe GmbH, Freiburg, Germany). Cell culture was performed under standard conditions at $37^{\circ} \mathrm{C}$ in a humidified atmosphere containing $5 \% \mathrm{CO}_{2}$.

\section{Chemicals}

MTX (Sigma-Aldrich, St. Louis, MO, USA) was prepared as a stock solution at a concentration of $20 \mathrm{mM}$ in $1 \mathrm{M}$ $\mathrm{NaOH}$ (Sigma) and stored at $-20{ }^{\circ} \mathrm{C}$ under light-free conditions. BUT and VAL (both from Sigma) were prepared as stock solutions at concentrations of $50 \mathrm{mM}$ in sterile PBS and 5AZA (Sigma) was prepared as a stock solution at a concentration of $1 \mathrm{mM}$ in sterile PBS. All three stock solutions were prepared freshly for each use. ATRA (Sigma) was prepared as a stock solution at concentration of $100 \mathrm{mM}$ in DMSO (Sigma) and stored at $-20^{\circ} \mathrm{C}$ under light-free conditions.

For the determination of proliferation activity, seven different concentrations of MTX ranging from 0.0001 to $100 \mu \mathrm{M}$ were tested. For all other experiments, concentrations of 1 and $40 \mu \mathrm{M}$ MTX were used. 5AZA, VAL and BUT served as positive controls and were used at the same concentration as MTX, i.e., 1 and $40 \mu \mathrm{M}$.

In experiments on matrix mineralization, $1 \mu \mathrm{M}$ ATRA was used as in previously published experiments concerning the ATRA-induced differentiation of osteosarcoma cells [30]. For the treatment of Saos-2 cells lower concentrations (i.e., $1 \mu \mathrm{M}$ MTX and $0.1 \mu \mathrm{M}$ ATRA) were used due to the previously reported sensitivity of these cells [30].

\section{MTT assay}

To evaluate cell proliferation, the MTT assay was used to detect the activity of mitochondrial dehydrogenases in 
Table 1 Description of the cell lines and characterization of their responses to MTX

\begin{tabular}{llllllll}
\hline Cell line & Gender & Age & Tumor type & Time of biopsy & DNA demethylation & $\begin{array}{l}\text { Increased histone H3 } \\
\text { acetylation }\end{array}$ & $\begin{array}{l}\text { MTX + ATRA enhanced } \\
\text { differentiation }\end{array}$ \\
\hline SaOS-2 & F & 11 & N/A & N/A & Y & N & N \\
OSA-02 & M & 21 & HGCC & DG & N & N & N \\
OSA-03 & M & 15 & HGCC & DG & Y & N & Y \\
OSA-05 & M & 9 & T & DG & Y & Y & Y \\
OSA-06 & F & 16 & O & DG & Y & N & N \\
OSA-08 & M & 10 & O & DG & Y & \\
\hline
\end{tabular}

Gender: $M$ male, $F$ female; Age at the time of diagnosis: years; Tumor type: $H G C C$ high grade conventional-chondroblastic, $T$ teleangiectatic, $O$ osteoblastic, $N / A$ information not available; Time of biopsy: DG diagnostic, N/A information not available; Responses to MTX, i.e. DNA demethylation, histone H3 acetylation; enhanced matrix mineralization: $Y$ yes, $N$ no

living cells. 96-well plates were seeded with $1 \times 10^{4}$ cells per well in $200 \mu \mathrm{l}$ of culture medium, and the cells were allowed to adhere overnight. The medium was removed and fresh medium containing the selected concentrations of chemicals described above or a control medium was added. The plates were incubated under standard conditions. To evaluate changes in cell proliferation, the medium was removed and replaced with $200 \mu \mathrm{l}$ of fresh DMEM containing 3-[4,5-dimethylthiazol-2-yl]-2,5-diphenyltetrazolium bromide (MTT) at $0.5 \mathrm{mg}$ per $\mathrm{ml}$. The plates were then incubated at $37{ }^{\circ} \mathrm{C}$ for $2.5 \mathrm{~h}$. The medium was carefully removed, and the formazan crystals were dissolved in $200 \mu \mathrm{l}$ of DMSO. The absorbance with a reference absorbance at $620 \mathrm{~nm}$ was measured at $570 \mathrm{~nm}$ using a Sunrise Absorbance Reader (Tecan, Männedorf, Switzerland).

\section{DNA methylation analysis}

Total DNA was extracted using a DNeasy Blood \& Tissue Kit (Qiagen, Hilden, Germany), and its concentration and purity was determined spectrophotometrically. Levels of 5-methylcytosine were detected using a 5-mC DNA ELISA Kit (Zymo Research Corporation, Irvine, CA, USA) according to the manufacturer's instructions. The absorbance was measured at $450 \mathrm{~nm}$ with the Sunrise Absorbance Reader.

\section{Global histone $\mathrm{H} 3$ acetylation}

For the specific measurement of global histone H3 acetylation, an EpiQuik Global Histone H3 Acetylation Assay Kit (Epigentek Group Inc., Farmingdale, NY, USA) was used according to the manufacturer's instructions. The absorbance was measured at $450 \mathrm{~nm}$ using the Sunrise Absorbance Reader.

\section{RT-qPCR}

The relative expression levels of selected genes were studied using RT-qPCR. Total RNA was extracted using the GenElute ${ }^{\mathrm{TM}}$ Mammalian Total RNA Miniprep kit
(Sigma), and its concentration and integrity was determined spectrophotometrically. For all samples, equal amounts of RNA (i.e., $25 \mathrm{ng}$ of RNA per $1 \mu \mathrm{l}$ of total reaction volume) were reverse transcribed into cDNA using M-MLV (Top-Bio, Prague, Czech Republic). RT-qPCR was carried out in $10 \mu \mathrm{l}$ using KAPA SYBR ${ }^{\circledR}$ FAST qPCR Kit (Kapa Biosystems, Wilmington, MA, USA) and analyzed using 7500 Fast Real-Time PCR System and 7500 Software v. 2.0.6 (both Life Technologies, Carlsbad, CA, USA). Changes in the transcript levels were calculated using $\mathrm{Cq}$ values standardized to a housekeeping gene (HSP90AB1), used as an endogenous reference gene control. Primers used for retinoic acid receptor alpha $(R A R A)$, retinoic acid receptor beta $(R A R B)$, retinoid $\mathrm{X}$ receptor alpha $(R X R A)$, retinol binding protein $1(R B P 1)$, cellular retinoic acid binding protein 2 (CRABP2), collagen type I (COLL I), alkaline phosphatase $(A L P L)$ and heat shock protein (HSP90AB1) are described in Table 2.

Table 2 Sequences of the primers used for qPCR

\begin{tabular}{|c|c|c|}
\hline Gene & Primer sequence & $\begin{array}{l}\text { Product } \\
\text { length (bp) }\end{array}$ \\
\hline RARA & $\begin{array}{l}\text { F: 5'-CGACCGAAACAAGAAGAAGAAGG-3' } \\
\text { R: 5'-TTCTGAGCTGTTGTTCGTAGTGT-3' }\end{array}$ & 166 \\
\hline$R A R B$ & $\begin{array}{l}\text { F: 5'-TGATGGAGTTGGGTGGACTT-3' } \\
\text { R: 5'-GCTTGGGACGAGTTCCTCAG-3' }\end{array}$ & 288 \\
\hline$R X R A$ & $\begin{array}{l}\text { F: 5'-CTCAATGGCGTCCTCAAGGT-3' } \\
\text { R: 5'-CACTCCATAGTGCTTGCCTGA-3' }\end{array}$ & 111 \\
\hline RBP1 & $\begin{array}{l}\text { F: 5'-TGACCGCAAGTGCATGACAA-3' } \\
\text { R: 5'-GACCACACCTTCCACTCTCA-3' }\end{array}$ & 142 \\
\hline CRABP2 & $\begin{array}{l}\text { F: 5'-TGCTGAGGAAGATTGCTGTG-3' } \\
\text { R: 5'-CCCATTTCACCAGGCTCTTA-3' }\end{array}$ & 183 \\
\hline COLLI & $\begin{array}{l}\text { F: 5'-CAGACTGGCAACCTCAAGAA-3' } \\
\text { R: 5'-GGAGGTCTTGGTGGTTTTGT-3' }\end{array}$ & 180 \\
\hline$A L P L$ & $\begin{array}{l}\text { F: 5'-CCACGTCTTCACATTTGGTG-3' } \\
\text { R: 5'-AGACTGCGCCTGGTAGTTGT-3' }\end{array}$ & 196 \\
\hline HSP9OAB1 & $\begin{array}{l}\text { F: 5'-CGCATGAAGGAGACACAGAA-3' } \\
\text { R: 5'-TCCCATCAAATTCCTTGAGC-3' }\end{array}$ & 169 \\
\hline
\end{tabular}




\section{Western blot analysis}

Nuclear protein extracts were harvested using NE-PER ${ }^{\mathrm{TM}}$ Nuclear and Cytoplasmic Extraction Reagents (Life Technologies, Carlsbad, CA, USA) according to the manufacturer's instructions. Total proteins $(15 \mu \mathrm{g})$ were loaded onto $10 \%$ polyacrylamide gels, electrophoresed, and blotted on polyvinylidene difluoride membrane (BioRad Laboratories, Munich, Germany). The membranes were blocked with $5 \%$ nonfat dry milk in PBS with $0.1 \%$ Tween-20 (Sigma) and incubated overnight either with rabbit polyclonal anti-acetyl-Histone H3 (Ac-Lys ${ }^{9}$ ) (No. H9286, Sigma, dilution 1:1000) or with mouse monoclonal anti-Proliferating Cell Nuclear Antigen (anti-PCNA) (No. P8825, clone PC10, Sigma, dilution 1:3000). Antimouse IgG antibody peroxidase conjugate (No. A9917, Sigma, dilution 1:10,000) or anti-rabbit IgG HRP-linked antibody (No. 7074, Cell Signaling Technology, Danvers, MA, USA, dilution 1:2000) was used as the secondary antibodies. ECL-Plus detection was performed according to the manufacturer's instructions (GE Healthcare, Little Chalfont, UK).

\section{Alizarin Red S staining}

Levels of extracellular matrix mineralization were evaluated using Alizarin Red S staining, which detects calcium compounds both in tissue sections and in vitro. The cells were seeded onto 12-well plates at concentrations of $1 \times 10^{4}$ (Saos- 2 cell line) or $5 \times 10^{3}$ (all OSA cell lines) cells per well and were cultivated in the presence or absence of ATRA and/or MTX for 21 days. The cultivation medium with these substances was renewed every 7 days. After 21 days of incubation, the medium was removed, the cells were washed with $\mathrm{PBS}$ and fixed with $3 \%$ paraformaldehyde in PBS at room temperature for $20 \mathrm{~min}$. Subsequently, the cells were incubated with $2 \%$ Alizarin Red S (Sigma) at room temperature for $45 \mathrm{~min}$. Thereafter, the cells were washed five times with deionized water and then with $70 \%$ ethanol for $30 \mathrm{~s}$. Red Alizarin dye was then dissolved via incubation with $100 \mathrm{mM}$ cetylpyridinium chloride (Sigma) at $50^{\circ} \mathrm{C}$ for $60 \mathrm{~min}$. The absorbance was measured at $450 \mathrm{~nm}$ also using the Sunrise Absorbance Reader.

\section{Statistical analysis}

The quantitative data are shown as mean \pm SD of three independent experiments. Data from MTT assays were analyzed using two-way ANOVA followed by the Scheffé post hoc test. $P<0.01$ was considered significant. The other data were analyzed using Student's t test. $P<0.05$ (two-sides) were considered statistically significant.

\section{Abbreviations}

AICAR transformylase: phosphoribosylaminoimidazolecarboxamide formyltransferase; 5AZA: 5-aza-2'-deoxycytidine; ATRA: all-trans retinoic acid; BUT: sodium butyrate; DHFR: dihydrofolate reductase; MAT: methionine adenosyltransferase; MTT: (3-(4,5-dimethylthiazol-2-yl)-2,5-diphenyltetrazolium bromide; MTX: methotrexate; PCNA: proliferating cell nuclear antigen; SAM: S-adenosylmethionine; TS: thymidylate synthase; VAL: sodium valproate.

\section{Authors' contributions}

MS carried out the experiments, analyzed the results and drafted the manuscript. JN designed this study, participated in analysis of results and in manuscript preparation. JS conceived and coordinated this study and participated in manuscript preparation. RV participated in the analysis of results and drafted the manuscript. All authors read and approved the final manuscript.

\section{Author details}

${ }^{1}$ Laboratory of Tumor Biology, Department of Experimental Biology, Faculty of Science, Masaryk University, Kotlarska 2, 61137 Brno, Czech Republic.

${ }^{2}$ Department of Pediatric Oncology, University Hospital Brno and Faculty of Medicine, Masaryk University, Cernopolni 9, 61300 Brno, Czech Republic

\section{Acknowledgements}

This study was supported by the grant IGA MZCR NT14327-3. The authors thank Dr. Jan Skoda and Dr. Petr Chlapek for skillful technical assistance.

\section{Competing interests}

The authors declare that they have no competing interests.

Received: 21 October 2015 Accepted: 12 February 2016

Published online: 29 February 2016

\section{References}

1. Hattinger CM, Fanelli M, Tavanti E, Vella S, Ferrari S, Picci P, et al. Advances in emerging drugs for osteosarcoma. Expert Opin Emerg Drugs. 2015;20:495-514.

2. Sterba J, Dusek L, Demlova R, Valik D. Pretreatment plasma folate modulates the pharmacodynamic effect of high-dose methotrexate in children with acute lymphoblastic leukemia and non-Hodgkin lymphoma: "folate overrescue" concept revisited. Clin Chem. 2006;52:692-700.

3. Sterba J, Valik D, Bajciova V. High-dose methotrexate in pediatric oncology—back to bench from bedside for a while? J Pediatr Hematol Oncol. 2009;31:151-2.

4. Cutolo M, Sulli A, Pizzorni C, Seriolo B, Straub RH. Anti-inflammatory mechanisms of methotrexate in rheumatoid arthritis. Ann Rheum Dis. 2001;60:729-35

5. Tian $\mathrm{H}$, Cronstein BN. Understanding the mechanisms of action of methotrexate: implications for the treatment of rheumatoid arthritis. Bull NYU Hosp Jt Dis. 2007;65:168-73.

6. Fotoohi AK, Albertioni F. Mechanisms of antifolate resistance and methotrexate efficacy in leukemia cells. Leuk Lymphoma. 2008;49:410-26.

7. McGuire JJ. Anticancer antifolates: current status and future directions. Curr Pharm Des. 2003;9:2593-613.

8. Singh R, Fouladi-Nashta AA, Li D, Halliday N, Barrett DA, Sinclair KD Methotrexate induced differentiation in colon cancer cells is primarily due to purine deprivation. J Cell Biochem. 2006;99:146-55.

9. Seitz M, Zwicker M, Loetscher P. Effects of methotrexate on differentiation of monocytes and production of cytokine inhibitors by monocytes. Arthritis Rheum. 1998;41:2032-8.

10. Hatse S, Naesens L, De Clercq E, Balzarini J. Potent differentiation-inducing properties of the antiretroviral agent 9-(2-phosphonylmethoxyethyl) adenine (PMEA) in the rat choriocarcinoma ( $\mathrm{RCHO}$ ) tumor cell model. Biochem Pharmacol. 1998;56:851-9.

11. Wu J, Wood GS. Reduction of Fas/CD95 promoter methylation, upregulation of Fas protein, and enhancement of sensitivity to apoptosis in cutaneous T-cell lymphoma. Arch Dermatol. 2011;147:443-9. 
12. Yang PM, Lin JH, Huang WY, Lin YC, Yeh SH, Chen CC. Inhibition of histone deacetylase activity is a novel function of the antifolate drug methotrexate. Biochem Biophys Res Commun. 2010;391:1396-9.

13. Wang YC, Chiang EP. Low-dose methotrexate inhibits methionine S-adenosyltransferase in vitro and in vivo. Mol Med. 2012;18:423-32.

14. Garattini E, Terao M. Cytodifferentiation: a novel approach to cancer treatment and prevention. Curr Opin Pharmacol. 2001;1:358-63.

15. Zhang L, Zhou Q, Zhang N, Li W, Ying M, Ding W, et al. E2F1 impairs alltrans retinoic acid-induced osteogenic differentiation of osteosarcoma via promoting ubiquitination-mediated degradation of RARa. Cell Cycle. 2014;13:1277-87.

16. Garattini E, Gianni M, Terao M. Retinoids as differentiating agents in oncology: a network of interactions with intracellular pathways as the basis for rational therapeutic combinations. Curr Pharm Des. 2007;13:1375-400.

17. Diede SJ, Guenthoer J, Geng LN, Mahoney SE, Marotta M, Olson JM, et al. DNA methylation of developmental genes in pediatric medulloblastomas identified by denaturation analysis of methylation differences. Proc Natl Acad Sci. 2010;107:234-9.

18. Virmani AK, Rathi A, Zöchbauer-Müller S, Sacchi N, Fukuyama Y, Bryant D, et al. Promoter methylation and silencing of the retinoic acid receptorbeta gene in lung carcinomas. J Natl Cancer Inst. 2000;92:1303-7.

19. Jaffe N, Gorlick R. High-dose methotrexate in osteosarcoma: let the questions surcease-time for final acceptance. J Clin Oncol. 2008;26:4365-6.

20. Hagner N, Joerger M. Cancer chemotherapy: targeting folic acid synthesis. Cancer Manag Res. 2010;2:293-301.

21. Veselska R, Hermanova M, Loja T, Chlapek P, Zambo I, Vesely K, et al. Nestin expression in osteosarcomas and derivation of nestin/CD133 positive osteosarcoma cell lines. BMC Cancer. 2008;8:300.

22. Neradil J, Pavlasova G, Sramek M, Kyr M, Veselska R, Sterba J. DHFRmediated effects of methotrexate in medulloblastoma and osteosarcoma cells: the same outcome of treatment with different doses in sensitive cell lines. Oncol Rep. 2015;33:2169-75.

23. Wang JJ, Li GJ. Relationship between RFC gene expression and intracellular drug concentration in methotrexate-resistant osteosarcoma cells. Genet Mol Res. 2014;13:5313-21.

24. Rihacek M, Pilatova K, Sterba J, Pilny R, Valik D. New indings in methotrexate pharmacology_diagnostic possibilities and impact on clinical care. Klin Onkol. 2015:28:163-70.

25. Bastian L, Einsiedel HG, Henze G, Seeger K, Shalapour S. The sequence of application of methotrexate and histone deacetylase inhibitors determines either a synergistic or an antagonistic response in childhood acute lymphoblastic leukemia cells. Leukemia. 2011;25:359-61.

26. Vezmar S, Schüsseler P, Becker A, Bode U, Jaehde U. Methotrexate-associated alterations of the folate and methyl-transfer pathway in the CSF of
ALL patients with and without symptoms of neurotoxicity. Pediatr Blood Cancer. 2009;52:26-32.

27. Kao TT, Lee GH, Fu CC, Chen BH, Chen LT, Fu TF. Methotrexate-induced decrease in embryonic 5-methyl-tetrahydrofolate is irreversible with leucovorin supplementation. Zebrafish. 2013;10:326-37.

28. Locasale JW. Serine, glycine and one-carbon units: cancer metabolism in full circle. Nat Rev Cancer. 2013:13:572-83.

29. Yang QJ, Zhou LY, Mu YQ, Zhou QX, Luo JY, Cheng L, et al. All-trans retinoic acid inhibits tumor growth of human osteosarcoma by activating Smad signaling-induced osteogenic differentiation. Int J Oncol. 2012;41:153-60.

30. Krzyzankova M, Chovanova S, Chlapek P, Radsetoulal M, Neradil J, Zitterbart $\mathrm{K}$, et al. LOX/COX inhibitors enhance the antineoplastic effects of all-trans retinoic acid in osteosarcoma cell lines. Tumour Biol. 2014;35:7617-27.

31. Patatanian E, Thompson DF. Retinoic acid syndrome: a review. J Clin Pharm Ther. 2008;33:331-8.

32. Cruz FD, Matushansky I. Solid tumor differentiation therapy-is it possible? Oncotarget. 2012;3:559-67.

33. Tomita A, Kiyoi H, Naoe T. Mechanisms of action and resistance to alltrans retinoic acid (ATRA) and arsenic trioxide (As2O3) in acute promyelocytic leukemia. Int J Hematol. 2013;97:717-25.

34. Crider KS, Yang TP, Berry RJ, Bailey LB. Folate and DNA methylation: a review of molecular mechanisms and the evidence for folate's role. Adv Nutr. 2012;3:21-38.

35. Widschwendter M, Berger J, Hermann M, Müller HM, Amberger A, Zeschnigk $M$, et al. Methylation and silencing of the retinoic acid receptor-beta2 gene in breast cancer. J Natl Cancer Inst. 2000;92:826-32.

36. Hayashi K, Yokozaki H, Goodison S, Oue N, Suzuki T, Lotan R, et al. Inactivation of retinoic acid receptor beta by promoter CpG hypermethylation in gastric cancer. Differentiation. 2001;68:13-21.

37. Aubin JE, Liu F, Malaval L, Gupta AK. Osteoblast and chondroblast differentiation. Bone. 1995;17(2):77-83.

38. Hatse S, De Clercq E, Balzarini J. Role of antimetabolites of purine and pyrimidine nucleotide metabolism in tumor cell differentiation. Biochem Pharmacol. 1999;58:539-55.

\section{Submit your next manuscript to BioMed Central and we will help you at every step:}

- We accept pre-submission inquiries

- Our selector tool helps you to find the most relevant journal

- We provide round the clock customer support

- Convenient online submission

- Thorough peer review

- Inclusion in PubMed and all major indexing services

- Maximum visibility for your research

Submit your manuscript at www.biomedcentral.com/submit
() Biomed Central 